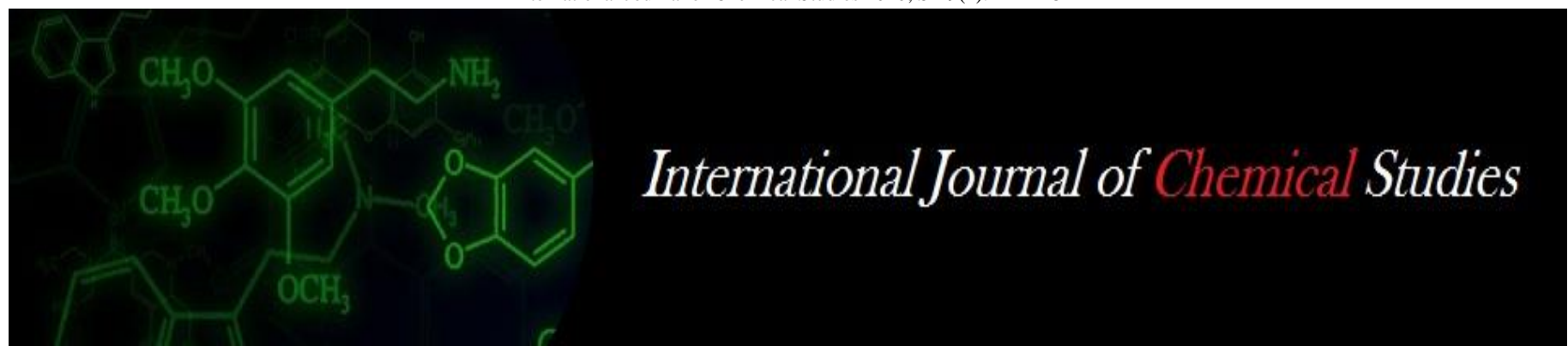

P-ISSN: 2349-8528

E-ISSN: 2321-4902

www.chemijournal.com

IJCS 2021; SP-9(1): 112-115

(C) 2021 IJCS

Received: 27-11-2020

Accepted: 30-12-2020

Sunidhi Mishra

Ph.D., Research Scholar, Department of FSN, CCAS, MPUAT, Udaipur, Rajasthan, India

Sarla Lakhawat

Associate Professor and Head Department of FSN, CCAS, MPUAT, Udaipur, Rajasthan, India

Kusum Sharma

Ph.D., Research Scholar, Department of FSN, CCAS, MPUAT, Udaipur, Rajasthan, India
Corresponding Author: Sunidhi Mishra

Ph.D., Research Scholar, Department of FSN, CCAS, MPUAT, Udaipur, Rajasthan, India

\section{Development and organoleptic evaluation of herbal mixture for prevention of Metabolic Syndrome}

\author{
Sunidhi Mishra, Sarla Lakhawat and Kusum Sharma
}

DOI: https://doi.org/10.22271/chemi.2021.v9.i1b.11452

\begin{abstract}
Metabolic syndrome describes a group of metabolic irregularities that occur together in an individual. The number of individuals diagnosed with metabolic syndrome has risen dramatically in recent years. Metabolic syndrome significantly raises the risk of developing cardiovascular disease and type 2 diabetes mellitus, obesity, and hypertension. Hence, the prevention of metabolic syndrome is need of the time. Therefore, it is seen that people are looking forward for herbal and natural products to overcome this syndrome, in this regard herbal mixture was developed with natural herbs namely tulsi, ginger, cinnamon, stevia, cardamom, black peeper etc. Trend panel members on 9-point hedonic scale standardized the herbal mixture through sensory evaluation. The best-selected herbal mixture was on twenty percent.
\end{abstract}

Keywords: Cardiovascular disease and type 2 diabetes mellitus, obesity

\section{Introduction}

Metabolic syndrome

In both developed and developing world, Metabolic syndrome (MetS) is prevalent as clinical challenge and escalating public health due to inactivity, urbanization and high energy intake in the form of processed foods, high obesity and sedentary life habits. Metabolic syndrome is the cluster of various diseases such as diabetes mellitus, obesity and risk of developing cardiovascular disease (CVD) over the next 5 to 10 years (Alberti et al. 2009) ${ }^{[2]}$.

\section{Cumin}

Cumin belongs to the family of Apiaceae (Cuminum cyminum L.) is mainly grown in arid and semi arid climate condition mainly in the country such as India, China, Iran and Indonesia. Cumin is aromatic herbaceous, thin and subglabrous dicotyledonous annual plant. Various compounds such as cuminal, $\beta$-myrcene, $\beta$-pinene, $\rho$-cymene, $\rho$-mentha-1,4-dien-7-ol and $\gamma$ terpinene. In terms of its cultivation, cumin is Homo sapiens as like coriander that also used as an alternative to pepper and can be used on the bread as paste spreading. It is also used as a spice in ethnic cuisines for its strong flavor around the world. (Mandal et al. 2016) ${ }^{[7]}$.

Ginger

Gingerol (1-[4'-hydroxy-3'- methoxyphenyl]-5-hydroxy-3-decanone) is the bioactive components from the rhizomes of ginger that exerts various physiological and pharmacological Properties. (Wilkinson 2000a) ${ }^{[16]}$.

\section{Fennel}

Fennel belongs to the family apiaceae known as Foeniculum vulgare (FVE) wic is majorly cultivated in native habitat as Egypt and India and has a long history of Herbal uses in the foods and famous for its strong edible flavored leaves and seeds (Roby et al. 2013). Fennel can be used in medicine and foods where traditionally it was acts as carminative (Flatulence control) and used for production of breast milk (Senatore et al. 2013), increase libido, promote menstrual flow, facilitate birth, sooths cough and indigestion (Namavar et al. 2003, Ostad et al. 2001) $)^{[9,10]}$. 


\section{Stevia}

Stevia rebaudiana is also considered as honey leaf. It can be safe for daily consumption in drinks not occasionally but many times in a day with no side-effects but dried leaves cannot be acceptable in domestic cooking as leaves green color (Rajbhandari and Roberts 1985, Tsanava et al. 1991) ${ }^{[11,15]}$.

\section{Black Peeper}

Black pepper (Piper nigrum L.) is considered as the "King of spices" which is widely used as flavor in the food and spice to enhance flavor, dishes and to enhance the taste of the food as main ingredients and can be used as spreads in pasta and pizza. It possess various bioactive phyto- compounds and biological properties (Critical Reviews in Food Science and Nutrition)

\section{Cardamom}

Cardamom (Elettaria cardamomum) is the family of Zingiberaceae. Cardamom have two subspecies such as Elettaria and Amomum in which green or true cardamom as Elettaria and black white, or red cardamom stands for Amomum (Mays et al., 2014) ${ }^{[8]}$.

\section{Cinnamon}

Overall, 250 species are identified among the cinnamon genus all over the world. Cinnamaldehyde and trans cinnamaldehyde are the main constituents present in
Cinnamon (Yeh et al. 2013) ${ }^{[4]}$.

\section{Carom seeds}

Carom seeds (C. copticum) belongs to the family of Apiaceae plants. It also called as Ajwain in Hindi. It is also an Egyptian aborigine plant which grows in arid and semi arid condition in the regions central Europe, Asia, India (Rajasthan, Gujarat, and West Bengal), Iraq, Afghanistan, Iran (Baluchistan) and Pakistan (Zargari et al. 1996, Zahin et al. 2010) ${ }^{[1,6]}$.

Carom seeds extensively used as food additive and also for therapeutic use in India and also known as Persian traditional medicine.

It also act as antidyspnea, antitussive, antilithiasis, amoebiasis expectorant, antiseptic, antiparasitic,

antimicrobial, antiplatelet-aggregatory, and bronchodilatory effect. It also helpful i gastrointestinal disorders, reflux, infection disorders, cramps, abdominal tumors, and abdominal pain (Zarshenas et. al. 2013) ${ }^{[5]}$.

\section{Tulsi}

Tulsi is famous by various names such as "The Queen of Herbs," "Mother Medicine of Nature," "elixir of life" and "The Incomparable One"that possess both type of properties as spiritual and medicinal Within Ayurveda (Singh et al. 2010) ${ }^{[14]}$.

\section{Methodology}

Table 1: Shows the Ingredients and its variation

\begin{tabular}{|c|c|c|c|c|c|c|c|}
\hline \multirow{2}{*}{ S. No. } & \multirow{2}{*}{ Ingredients } & \multicolumn{6}{|c|}{ Variations } \\
\cline { 3 - 8 } & & $\mathbf{5 \%}$ & $\mathbf{1 0 \%}$ & $\mathbf{1 5 \%}$ & $\mathbf{2 0 \%}$ & $\mathbf{2 5 \%}$ & $\mathbf{3 0 \%}$ \\
\hline 1. & Herbal Powder & $10 \mathrm{~g}$ & $20 \mathrm{~g}$ & $30 \mathrm{~g}$ & $40 \mathrm{~g}$ & $50 \mathrm{~g}$ & $60 \mathrm{~g}$ \\
\hline 2. & Cumin seeds & $5 \mathrm{~g}$ & $5 \mathrm{~g}$ & $5 \mathrm{~g}$ & $5 \mathrm{~g}$ & $5 \mathrm{~g}$ & $5 \mathrm{~g}$ \\
\hline 3. & Carom seeds & $5 \mathrm{~g}$ & $5 \mathrm{~g}$ & $5 \mathrm{~g}$ & $5 \mathrm{~g}$ & $5 \mathrm{~g}$ & $5 \mathrm{~g}$ \\
\hline 4. & Fennel seeds & $20 \mathrm{~g}$ & $20 \mathrm{~g}$ & $20 \mathrm{~g}$ & $20 \mathrm{~g}$ & $20 \mathrm{~g}$ & $20 \mathrm{~g}$ \\
\hline 5. & Black peeper & $0.5 \mathrm{~g}$ & $0.5 \mathrm{~g}$ & $0.5 \mathrm{~g}$ & $0.5 \mathrm{~g}$ & $0.5 \mathrm{~g}$ & $0.5 \mathrm{~g}$ \\
\hline 6. & Black salt & $0.2 \mathrm{~g}$ & $0.2 \mathrm{~g}$ & $0.2 \mathrm{~g}$ & $0.2 \mathrm{~g}$ & $0.2 \mathrm{~g}$ & $0.2 \mathrm{~g}$ \\
\hline & Total Weight of Mixture & $40.7 \mathrm{~g}$ & $50.7 \mathrm{~g}$ & 60.7 & 70.7 & 80.7 & 90.7 \\
\hline
\end{tabular}

\section{Method of Preparation \\ Herbal mixture}

- Cumin seeds, Carom Seeds, Fennel Seeds were Roasted at low flame for 5 to 10 minutes.

- All the roasted seeds were grind separately

- Seeds powder was prepared after grinding.

- Further, Herbal Powder was added at different ratio such as $5,10,15,20,25$ and 30 with prepared herbal seed powder

- Black salt and Black pepper were added in herbal powder

- Finally herbal mixture was prepared.

\section{Sensory evaluation of developed products}

The acceptability of gravies was evaluated by a panel of 10 judges using 9-point Hedonic Scale (Ranganna, 1986) to test the liking or disliking of products. Semi -trained panel did the evaluation. The panelist asked to record the level of liking or disliking by giving marks for various characteristics of the products. The samples were rated on 9-point Hedonic Scale for quality attributes according to following grade descriptions and scoring.
Result and Discussion: Development and Distribution of Herbal premix - various products were developed with the use of herbal premix further physiochemical and shelf life assessment of premix was evaluated and dietary intervention of premix was observed on selected subjects for ninety days. In the present study, Herbal mixture were prepared with the variation of $5 \%, 10 \%, 15 \%, 20 \%, 25 \%$ and $30 \%$ in corporation with herbal premix and the mean score assigned for its attributes by panel members has been presented in the above table that depicted the highest score for all sensory attributes was at 20\%. Among the treatment of herbal mixture, it was found that in color, $20 \%(7.83 \pm 0.7)$ with followed by control $(6.25 \pm 0.13)$, and $25 \%(5.07 \pm 2.21)$ was accepted. In appearance at $20 \%(8.07 \pm 0.49)$ with control $(6.57 \pm 0.21)$ and next to $30 \%(6.6 \pm 0.46)$.Similar, pattern was observed in other sensory attributes of herbal mixture.

Statistical data revealed that there was significant difference in a mean score for color at $10 \%(3.97 \pm 0.96)$, Aroma $25 \%(3.57 \pm 1.15)$ and over acceptability was on $10 \%(6.77 \pm 0.6)$ and $20 \%(8.63 \pm 0.25)$ whereas highly significant mean score were observed in appearance $10 \%(4.49 \pm 1.54)$ and $15 \%(4.43 \pm 0.12)$ with compare to other variation. 
Table 2: Mean Acceptability scores of Herbal Mixture prepared by incorporating Herbal Premix

\begin{tabular}{|c|c|c|c|c|c|c|c|c|c|c|c|c|}
\hline \multicolumn{13}{|c|}{ Sensory Evaluation of Herbal Mixture } \\
\hline \multirow{2}{*}{ Variation } & \multicolumn{2}{|c|}{ Colour } & \multicolumn{2}{|c|}{ Appearance } & \multicolumn{2}{|c|}{ Texture } & \multicolumn{2}{|c|}{ Aroma } & \multicolumn{2}{|c|}{ Taste } & \multicolumn{2}{|c|}{$\begin{array}{c}\text { Overall } \\
\text { Acceptability }\end{array}$} \\
\hline & Mean & SD & Mean & SD & Mean & SD & Mean & SD & Mean & SD & Mean & SD \\
\hline Control & 6.25 & 0.13 & 6.57 & 0.21 & 7.53 & 0.35 & 6.6 & 0.3 & 6.72 & 0.2 & 7.52 & 0.39 \\
\hline $5 \%$ & 5.5 & 1 & 5.1 & 1.71 & 6.03 & 1.27 & 5.37 & 1.51 & 7.33 & 1.32 & $6.77 \#$ & 0.6 \\
\hline $10 \%$ & $3.97 \#$ & 0.76 & 4.9\# & 1.54 & 5.87 & 0.67 & 5.37 & 1.85 & 7.03 & 0.67 & 7.23 & 0.42 \\
\hline $15 \%$ & 5.27 & 0.97 & 4.43\# & 0.12 & 5.67 & 1.52 & 4.93 & 1.8 & 6 & 1.13 & 7.17 & 0.31 \\
\hline $20 \%$ & 7.83 & 0.7 & 8.07 & 0.49 & 8.03 & 0.38 & 7.77 & 0.29 & 7.8 & 0.36 & $8.63 \#$ & 0.25 \\
\hline $25 \%$ & 5.07 & 2.21 & 5.13 & 0.55 & 5.17 & 0.85 & $3.57 \#$ & 1.15 & 5.87 & 0.57 & 7.17 & 0.32 \\
\hline $30 \%$ & 4.4 & 0.85 & 6.6 & 0.46 & 5.87 & 2.41 & 6.63 & 0.51 & 7.03 & 0.9 & 7.8 & 0.4 \\
\hline F-value & \multicolumn{2}{|c|}{3.980} & \multicolumn{2}{|c|}{5.728} & \multicolumn{2}{|c|}{2.087} & \multicolumn{2}{|c|}{3.685} & \multicolumn{2}{|c|}{2.135} & \multicolumn{2}{|c|}{6.924} \\
\hline$p$-value & \multicolumn{2}{|c|}{$.016^{*}$} & \multicolumn{2}{|c|}{$.003 * *$} & \multicolumn{2}{|c|}{.120} & \multicolumn{2}{|c|}{$.021 *$} & \multicolumn{2}{|c|}{.114} & \multicolumn{2}{|c|}{$.001 * *$} \\
\hline
\end{tabular}

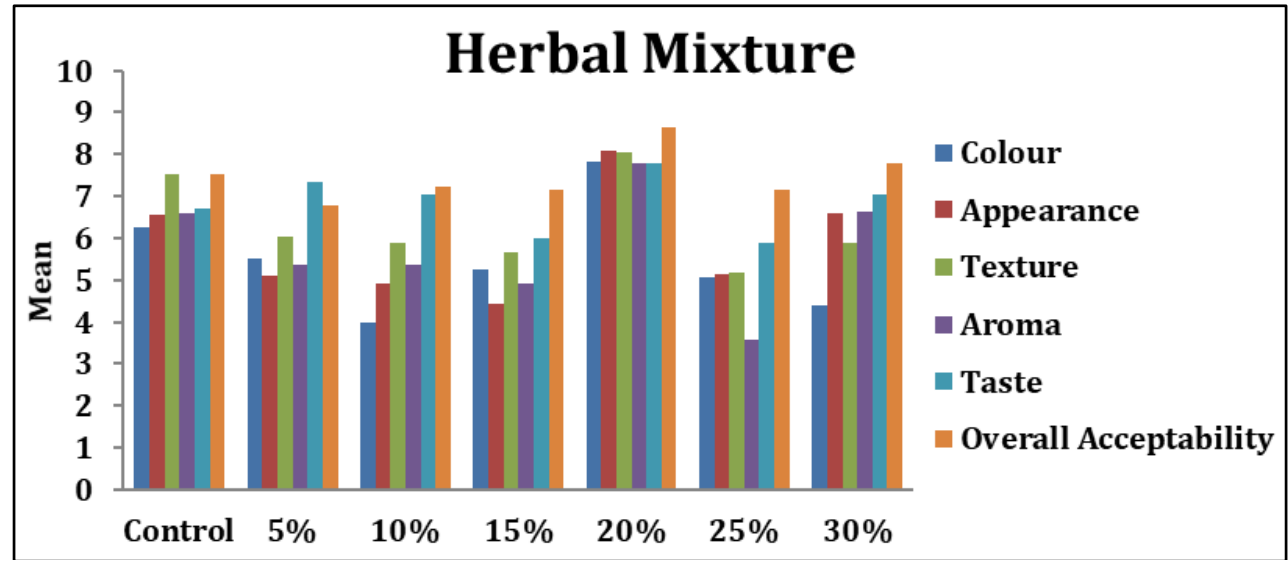

Fig 1: Mean Acceptability scores of Herbal Mixture prepared by incorporating Herbal Premix

It is noted from the above data that the panel list like herbal mixture with $20 \%$ incorporation of herbal products on the overall basis and $20 \%$ herbal mixture was selected for the further investigation of the study.

\section{Conclusion}

Metabolic syndrome is defined as combination of various disease such as obesity, diabetes mellitus and hypertension e.t.c. due to lack of time, activity, sedentary lifestyle, consumption of processed foods such as juice ready to eat foods that undergoes high heat production. Thus, people are keenly interested towards herbal products and organic foods that have no side effects and safe for consumption.

Hence, in this study herbal mixture was prepared with the use of various herbs such as cumin seeds, fennel, black pepper, ginger, cinnamon, cardamom e.t.c at different variation further it was evaluated by the selected panel members at 9 point hedonic scale on the variables color, texture, taste e.t.c in which highest acceptability was given to $20 \%$ of herbal mixture.

\section{Acknowledgement:}

I greatly acknowledge DST-INSPIRE for providing research fellowship. I also acknowledge the department of food science and nutrition, CCAS, MPUAT Udaipur for proving all research facilities.

\section{References}

1 Zargari, Herb, vol. 2, Tehran University, Tehran, Iran, 6th edition 1996.

2 Alberti KGMM, Eckel RH, Grundy SM, et al. Harmonizing the metabolic syndrome: a joint interim statement of the international diabetes federation task force on epidemiology and prevention; National heart, lung, and blood institute; American heart association; World heart federation; International atherosclerosis society; And international association for the study of obesity. Circulation 2009;120(16):1640-1645. [PubMed] [Google Scholar]

3 Critical Reviews in Food Science and Nutrition Volume 59, 2019 - Issue sup1: 3rd International Symposium on Phytochemicals in Medicine and Food (3-ISPMF, August 25-29 2018, Kunming, China); Guest editors: Jianbo Xiao and Weibin Bai

4 Yeh HF, Luo CY, Lin CY, Cheng SS, Hsu YR, Chang ST, et al. Methods for thermal stability enhancement of leaf essential oils and their main Constituents from Indigenous Cinnamon (Cinnamomum osmophloeum)," Journal of Agricultural and Food Chemistry 2013;61(26):6293-6298.

5 Zarshenas MM, Moein M, Samani SM, Petramfar P. An overview on ajwain (Trachyspermum ammi) pharmacological effects; modern and traditional," Journal of Natural Remedies 2013;14(1):98-105.

6 Zahin M, Ahmad I, Aqil F. Antioxidant and antimutagenic activity of Carum copticum fruit extracts," Toxicology in Vitro 2010;24(4):1243-1249.

7 Manisha Mandal, Shyamapada Mandal, in Essential Oils in Food Preservation, Flavor and Safety 2016.

8 Mays Hadi Jebur, Ilham A Bnuyan, Amean A Yasri, Nada Khazal Kadhim Hindi. Antimicrobial Effect of Seed Extracts, leaves and Crude oil of Cardamom (Elettaria cardamomum) against different types of Bacteriain Hilla City, Iraq; World Journal of Pharmaceutical Research 2014;3(3).

9 Namavar JB, Tartifizadeh A, Khabnadideh S. Comparison of fennel and mefenamic acid forthe 
treatment of primary dysmenorrhea. Int $\mathrm{J}$ Gynaecol Obstet 2003;80:153-7.

10 Ostad SN, Soodi M, Shariffzadeh M, Khorshidi N, Marzban H. The effect of fennel essential oil on uterine contraction as a model for dysmenorrhea, pharmacology and toxicology study. J Ethnopharmacol 2001;76:299304.

11 Rajbhandari A, Roberts M. The flavonoids of Stevia microchaeta, Stevia monardifolia, and Stevia origanoides. J Nat Prod 1985;48(3):502-503.

12 Roby MH, Sarhana MA, Selima KA, Khalela KI. Antioxidant and Antimicrobial Activities of Essential Oil and Extracts of Fennel (Foeniculum vulgare L.) and Chamomile (Matricaria chamomilla L.). Ind Crop Prod 2013;44:437-45.

13 Senatore F, Oliviero F, Scandolera E, Taglialatela-Scafati $\mathrm{O}$, Roscigno $\mathrm{G}$, Zaccardelli $\mathrm{M}$, et al. Chemical composition, antimicrobial and antioxidant activities of anethole-rich oil from leaves of selected varieties of fennel Foeniculum vulgare Mill. ssp. vulgare var. azoricum (Mill.) Thell. Fitoterapia 2013;90:214-9.

14 Singh N, Hoette Y, Miller R. Tulsi: The Mother Medicine of Nature. 2nd ed. Lucknow: International Institute of Herbal Medicine 2010, 28-47.

15 Tsanava VP, Sardzhveladze GP, Kharebava LG. Effect of technological procedures on the composition of volatile substances in Stevia rebaudiana Chem Abstr 1991;116:82-87.

16 Wilkinson JM. Effect of ginger tea on the fetal development of Sprague-Dawley rats. Reprod Toxicol 2000a;14(6):507-12. [PubMed] 